applied them. The ordinary user is still left wondering which is the best to use. Usually it was applied by the station personnel. The cooling effect of water gives it a tremendous advantage over carbon dioxide, methyl bromide or carbon tetrachloride. Accepting this, he suggested that for outdoor and indoor transformers and oil and bitumen-filled switchgear, an automatic atomized water installation might be used, and for cable basements and cellars where oil is not likely to be present, ordinary sprinklers would suffice. Finally, he prefers a water pressure of $60 \mathrm{lb}$. per sq. in and a ten minutes storage supply to the $50 \mathrm{lb}$. and four or five minutes recommended in the report.

Mr. C. M. Kerr, who is an officer of the London Fire Brigade and was also a member of the Fire Committee concerned with these tests, spoke of the difficulty of laying down hard-and-fast rules for dealing with these fires and emphasized the need of ample back-up protection; to this, he thinks, too little attention has been given in the report. He also mentioned the need for attention being given to the maintenance of the various forms of fire fighting equipment as a consideration in determining their choice.

Mr. H. Bright said that although the title of the report was "Fire Fighting Equipment for Electrical Installations", it dealt, as did the discussion, solely with power stations. There are, however, installations, such as those in places of entertainment and elsewhere, where the risk of life from oil fires is very much greater than in power stations. In such cases, certain of the media mentioned must be ruled out because of their toxic or suffocating effects. In such places, too, it would be impossible to drain the oil from the transformers into pits, as was suggested for power stations. The alternative seemed to be to have a large tank.

Mr. Hacking, who replied to the discussion, said that the word 'emulsification' was deliberately not used in the report, because satisfactory results had been obtained using water, when there was no question of emulsification. He agreed that the smoke detector should only be used as a detector.

\title{
INSECT PESTS OF CROPS IN ENGLAND AND WALES
}

\author{
By DR. A. D. IMMS, F.R.S.
}

$\mathrm{B}^{\mathrm{r}}$ ULLETIN No. 118 of the Ministry of Agriculture and Fisheries, recently issued, records the incidence of the more important crop pests for the years 1935-37. The information upon which it is based has been supplied in the main by the advisory entomologists and other reporters. It appears that numerous foreign insects were intercepted by the Ministry's inspectors during their examination of imported plants and others were sent in by the general public. The great majority of these aliens were unlikely to prove either injurious or to establish themselves in Great Britain. A few, however, were of a different category and need brief reference.

The Colorado beetle (Leptinotarsa decemlineata) was represented by a few individuals found in the vicinity of London and Swansea. For the most part they were known to have been introduced through shipping, but no outbreak occurred during the period under review. The chrysanthemum midge (Diarthronomyia sp.) first occurred as an outbreak in 1927 but, by 1930, the pest was reported to have been eradicated. After an interval of six years a new infestation was discovered in southern England and appears to have had origin in plants or cuttings imported from the United States. In order to render the position more secure in future the importation of chrysanthemums has now been prohibited, except under special licence, which prescribes rigorous precautions to be observed.

The asparagus fly (Platyparea pociloptera) had not been previously noted in England until it was discovered by $\mathrm{C}$. Warburton in a garden in Hertfordshire in 1935. Subsequent work carried out by the Ministry's inspectors showed that it is too widely established in that county to render any attempt at eradication practicable. The species is a serious asparagus pest on the Continent of Europe and its presence in England may result in the shortening of the productive life of the beds, but it is probable that reasonable commercial control will be attained.

During the period under review, while many of the regular pests of English crops were prevalent, relatively few are specially noteworthy. Mention, however, must be made of the codling moth, which caused very serious damage in most fruit-growing districts during 1935 although it was much less troublesome in the two succeeding years. On the upland pastures of mid-Wales and parts of northern England, outbreaks of larvæ of the antler moth caused loss of sheep-keep. Wheat and oats were seriously attacked by the aphid Myzus festucae in 1935, large acreages in many districts being almost completely ruined. As with the codling moth, the attacks were much less evident in the other two years.

Among unusual records larvæ of the sword grass moths (Polia vestusta and exoleta) attacking hops and of the holly blue butterfly (Lycoena argiolus) injuring raspberries are of interest.

The bulletin also gives a summary of progress as regards insecticides and their application, and concludes with a useful list of references to papers published in Great Britain, during the triennial period, which are concerned with crop pests and related subjects. Viewed as a whole the situation is very satisfactory. Possible danger from the introduction of the apple maggot from Canada and the United States and of the cherry fruit fly from various European countries has been reduced to small proportions by timely action being taken. Also the well-organized watch kept for the Colorado beetle has amply justified itself, since no outbreak has occurred; yet, on the Continent of Europe, its spread eastwards extends yearly and it now has an almost continuous range from southern France to central Germany. 